\title{
Peningkatan Perilaku Tentang Diet Sehat di Panti Asuhan Yatim Piatu dan Dhuafa Yayasan Al 'Ashr Banjarmasin 2019
}

\author{
Yeni Riza ${ }^{1}$, Erwin $_{\text {Ernadi }}{ }^{2}$ Mahmudah $^{3}$ \\ ${ }^{1,2,3}$ Fakultas Kesehatan Masyarakat Universitas Islam Kalimantan MAB Banjarmasin \\ Email: yeniriza86@gmail.com
}

Submitted : 10/09/2020

Accepted: 24/09/2020

Published: 24/11/2020

\begin{abstract}
A healthy lifestyle is an effort that someone does consistently to stay in a healthy and optimal condition. Healthy lifestyle is not uncommon as an effort that is not easy so it is difficult to implement, even though it will be even more difficult if we have become sick because they do not run a healthy lifestyle. The Orphanage Orphanage and Dhuafa Foundation Al 'Ashr Banjarmasin is one of the orphanages in the city of Banjarmasin. Imbalance between food consumed with needs is the cause of malnutrition problems and over nutrition problems, so that children in this orphanage also have the risk of under nutrition problems and more due to lack of knowledge about a healthy diet. Therefore This community service activity will be held for children and adolescents of the Orphanage Orphanage and Dhuafa Foundation Al 'Ashr Banjarmasin in order to prevent nutritional problems due to inappropriate dietary patterns. The purpose of the activity is to provide knowledge for children and young people of the Orphanage Orphanage and Dhuafa Foundation Al 'Ashr Banjarmasin on a healthy diet for the body's needs to create a healthy young generation. The main targets or specific targets of this activity are children and young people of the Orphanage Orphanage and Dhuafa Foundation Al 'Ashr Banjarmasin. The method used in this activity is through video screenings, lectures, and discussions and questions and answers. The counseling activity was carried out on December 8, 2019, attended by 18 orphans. Activities take place smoothly and in an orderly manner. Increased knowledge about healthy diets in adolescents at the Orphanage Orphanage and the Al $r$ Ashr Foundation Dhuafa, Increased skills in carrying out body examinations conducted independently such as measuring waist circumference, heart rate tests, oral health, nails etc.
\end{abstract}

Keywords: diet, healthy, orphanage, teenager

\begin{abstract}
Abstrak
Pola hidup sehat adalah suatu usaha yang dilakukan seseorang secara konsisten untuk tetap dalam keadaan sehat dan optimal. Pola hidup sehat tidak jarang dianggap sebagai suatu upaya yang tidak mudah sehingga sulit untuk diterapkan, padahal akan lebih sulit lagi jika kita sudah menjadi sakit karena tidak menjalankan pola hidup sehat tersebut. Panti Asuhan Yatim Piatu dan Dhuafa Yayasan Al 'Ashr Banjarmasin adalalah salah satu panti asuhan yang ada di kota Banjarmasin. Ketidak seimbangan antara makanan yang dikonsumsi dengan kebutuhan adalah penyebab masalah gizi kurang dan masalah gizi lebih, sehingga anak-anak yang ada di panti asuhan ini juga memiliki resiko terjadinya masalah gizi kurang dan lebih karena kekurangan dalam hal pengetahuan mengenai diet yang sehat.Oleh karena itu akan diadakan kegiatan pengabdian masyarakat ini untuk para anak dan remaja Panti Asuhan Yatim Piatu dan Dhuafa Yayasan Al 'Ashr Banjarmasin agar dapat mencegah terjadinya masalah gizi karena pola diet yang kurang tepat. Tujuan kegiatan adalah untuk memberikan pengetahuan bagi para anak dan remaja Panti Asuhan Yatim Piatu dan Dhuafa Yayasan Al 'Ashr Banjarmasin tentang diet yang sehat bagi kebutuhan tubuh agar menciptakan generasi muda yang sehat. Sasaran utama atau target khusus dari kegiatan ini adalah anak dan remaja Panti Asuhan Yatim Piatu dan Dhuafa Yayasan Al 'Ashr Banjarmasin. Metode yang digunakan dalam kegiatan ini adalah melalui pemutaran video, ceramah, dan diskusi serta tanya jawab. Kegiatan penyuluhan telah dilaksanakan pada tanggal 8 Desember 2019, dihadiri oleh 18 anak yatim. Kegiatan berlangsung dengan lancar dan tertib. Meningkatnya pengetahuan tentang diet sehat pada anak remaja di Panti Asuhan Yatim Piatu dan Dhuafa Yayasan Al 'Ashr,
\end{abstract}


Meningkatnya keterampilan dalam melakukan pemeriksaan tubuh yang dilakukan secara mandiri seperti mengukur lingkar pinggang, tes denyut jantung, kesehatan mulut, kuku dll.

Kata Kunci: diet, panti asuhan, remaja, sehat

\section{PENDAHULUAN}

Pola hidup sehat adalah suatu usaha yang dilakukan seseorang secara konsisten untuk tetap dalam keadaan sehat dan optimal. Pola hidup sehat dilakukan dengan cara memperhatikan kebutuhan nutrisi dalam tubuh, berolah raga, istrahat dan berpikiran yang positif. Pola hidup sehat tidak jarang dianggap sebagai suatu upaya yang tidak mudah sehingga sulit untuk diterapkan, padahal akan lebih sulit lagi jika kita sudah menjadi sakit karena tidak menjalankan pola hidup sehat tersebut. Dalam bahasa Indonesia, Diet lebih sering ditujukan untuk menyebut suatu upaya dalam menurunkan atau mengatur asupan nutrisi tertentu. Pengertian diet lainnya yaitu " kegiatan membatasi nutrisi berupa kalori dengan sengaja, yang dimaksudkan untuk mendapatkan bentuk tubuh yang lebih kurus".Dapat diartikan bahwa perilaku diet ini menekankan pada usaha penurunan berat badan yang dapat dilakukan dengan berbagai cara namun tetap berfokus pada pengaturan pola makan oleh pelaku diet.

Panti Asuhan Yatim Piatu dan Dhuafa Yayasan Al 'Ashr Banjarmasin adalah salah satu panti asuhan yang ada di kota Banjarmasin. Ketidak seimbangan antara makanan yang dikonsumsi dengan kebutuhan adalah penyebab masalah gizi kurang dan masalah gizi lebih, sehingga anak-anak yang ada di panti asuhan ini juga memiliki resiko terjadinya masalah gizi kurang dan lebih karena kekurangan dalam hal pengetahuan mengenai diet yang sehat.Oleh karena itu akan diadakan kegiatan pengabdian masyarakat ini untuk para anak dan remaja Panti Asuhan Yatim Piatu dan Dhuafa Yayasan Al 'Ashr Banjarmasin agar dapat mencegah terjadinya masalah gizi karena pola diet yang kurang tepat.

\section{TARGET DAN LUARAN}

Target pengabdian masyarakat ini adalah terlaksananya kegiatan penyuluhan tentang diet sehat di Panti Asuhan Yatim Piatu dan Dhuafa Yayasan Al 'Ashr sehingga dapat menigkatkan pengetahuan, memberikan pelatihan-pelatihan dalam pemeriksaan tubuh yang dilakukan secara mandiri seperti mengukur lingkar pinggang, tes denyut jantung, kesehatan mulut, kuku dll. Serta memberikan video dan poster edukasi untuk dapat meningkatkan kesadaran, kemauan dan kemampuan dalam mempertahan hidup sehat.

Luaran yang dicapai pengabdian masyarakat ini adalah Meningkatnya pengetahuan tentang diet sehat di Panti Asuhan Yatim Piatu dan Dhuafa Yayasan Al 'Ashr, meningkatnya keterampilan dalam melakukan pemeriksaan tubuh yang dilakukan secara mandiri seperti mengukur lingkar pinggang, tes denyut jantung, kesehatan mulut, kuku dll. Luaran lainnya yaitu Artikel pengabdian ini akan dipublikasikan pada Jurnal ilmiah Pengabdian Kepada Masyarakat ber ISSN/Prosiding

\section{METODE PELAKSANAAN}

Waktu pelaksanaan pengabdian masyarakat ini pada tanggal 8 Desember 2019. Khalayak sasaran yang dijadikan untuk kegiatan ini adalah 18 anak Panti Asuhan Yatim Piatu dan Dhuafa Yayasan Al 'Ashr Banjarmasin. Metode yang digunakan dalam kegiatan ini adalah melalui pemutaran video, ceramah, dan diskusi serta tanya jawab.

\section{HASIL DAN PEMBAHASAN}

Pelaksanan kegiatan penyuluhanan ini diawali dengan melakukan perizinan dan berkoordinasi terlebih dahulu dengan pengelola Panti Asuhan Yatim Piatu dan Dhuafa Yayasan Al 'Ashr dalam 
menentukan jadwal dan sasaran anak-anak yang akan dilakukan penyuluhan. Penyuluhan tentang diet sehat di Panti Asuhan Yatim Piatu dan Dhuafa Yayasan Al 'Ashr dilaksanakan pada hari Rabu 18 Desember 2019 bertempat di ruang kumpul Panti Asuhan Yatim Piatu dan Dhuafa Yayasan Al 'Ashr Banjarmasin. Kegiatan penyuluhan diawali dengan perkenalan dilanjutkan dengan pemberian materi tentang Diet Sehat, kemudian dilanjutkan dengan tanya jawab atau diskusi. Untuk mengetahui pengetahuan anak-anak sebelum dan sesudah diberikan penyuluhan maka tim pelaksana melakukan evaluasi pretest dan posttest penyuluhan, sehingga anak-anak lebih memahami tentang diet sehat. Pada kegiatan pengabdian ini tim juga melatih anak-anak remaja di panti asuhan untuk mengenali dan mampu melakukan pemeriksaan fisik yang dapat mereka lakukan secara mandiri seperti, mengukur lingkar pinggang, tes denyut jantung, kesehatan mulut, kuku dll.

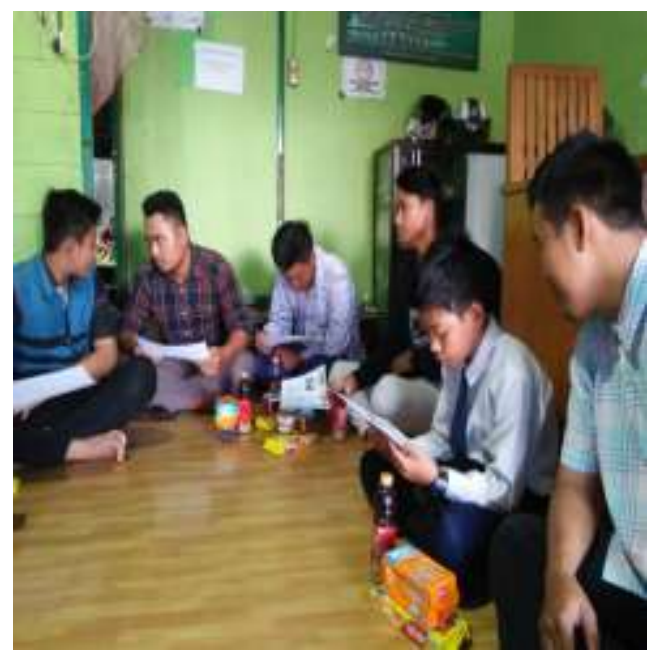

Gambar 1. Peserta penyuluhan sedang fokus membaca lembar leaflet

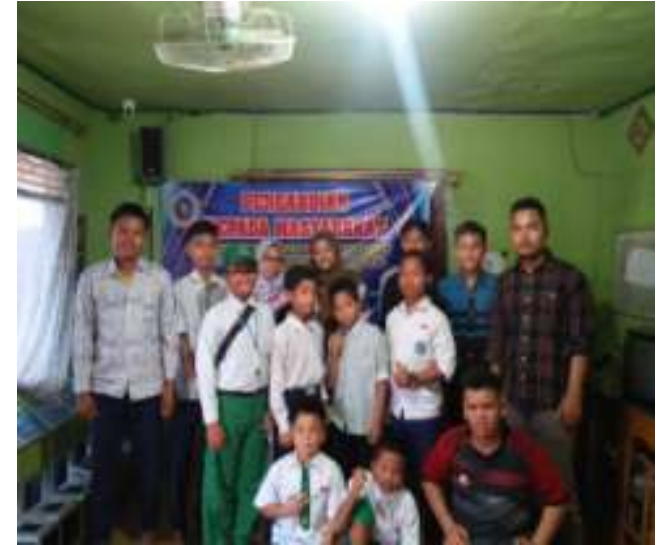

Gambar 2. Berfoto bersama peserta penyuluhan di Panti Asuhan Yatim Piatu

\section{KESIMPULAN DAN SARAN}

Kesimpulan yang dapat diambil setelah dilakukan kegiatan pengabdian kepada masyarakat ini adalah meningkatnya pengetahuan anak-anak dan remaja yang mendapatkan penyuluhan tentang diet sehat ditandai dengan lebih dari $80 \%$ (16 peserta) mampu menjawab pertanyaan yang diajukan oleh tim penyuluhan, sedangkan sisanya ( 2 peserta) masih tampak ragu dan belum mampu untuk menjawab pertanyaan terkait diet sehat. Meningkatnya keterampilan ditandai dengan mampunya peserta dalam melakukan pemeriksaan tubuh yang dilakukan secara mandiri seperti mengukur lingkar pinggang, tes denyut jantung, kesehatan mulut, kuku dll.

\section{UCAPAN TERIMAKASIH}

Ucapan terimakasih kami sampaikan kepada Universitas Islam Kalimantan MAB Banjarmasin yang telah mendanai kegiatan pengabdian ini, kepada Dekan FKM Uniska yang telah memberikan perizinan dan kepada Yayasan Al 'Ashr Banjarmasin yang telah memberikan izin, serta teman-teman dosen dan mahasiswa yang telah banyak membantu. Sekolah Tinggi Ilmu Kesehatan Baiturrahim Jambi yang telah memfasilitasi kegiatan ini, dan tak lupa kepada semua 
Jurnal Abdimas Kesehatan (JAK) Vol 2, No 3, November 2020

DOI: $10.36565 /$ jak.v2i3.137

p-ISSN: 2655-9266

e-ISSN: 2655-9218

pihak yang telah membantu kegiatan kepada masyarakat ini.

Akhmad, E. 2011. Diet Sehat untuk Remaja. Kanisius: Yogyakarta.

Nirwana, AE.2011. Psikologi Kesehatan Wanita. Nuha Medika: Yogyakarta

DAFTAR PUSTAKA

Adya, R. 2011. Serba Serbi Diet Sehat: Kumpulan Metode Diet Pilihan Yang Mudah dan Praktis. Bukune,Jakarta.

Notoatmodj,S, 2010. Metodologi Penelitian Kesehatan. Edisi Revisi Rineka cipta: Jakarta. 